OPEN ACCESS

Edited by:

Mariana Gisela Bego,

McGill University, Canada

Reviewed by:

Alexis Palmer-Fluevog,

McGill University, Canada

*Correspondence:

Wilson Lewis Mandala

wmandala@must.ac.mw

Michael K. P. Liu

michael.liu@imperial.ac.uk

Specialty section: This article was submitted to Viral Immunology,

a section of the journal

Frontiers in Immunology

Received: 18 October 2021 Accepted: 25 October 2021 Published: 08 November 2021

Citation:

Mandala WL and Liu MKP (2021) SARS-CoV-2 and HIV-1: Should HIV1-Infected Individuals in Sub-Saharan Africa Be Considered a Priority Group for the COVID-19 Vaccines?

Front. Immunol. 12:797117. doi: 10.3389/fimmu.2021.797117

\section{SARS-CoV-2 and HIV-1: Should HIV- 1-Infected Individuals in Sub-Saharan Africa Be Considered a Priority Group for the COVID-19 Vaccines?}

\author{
Wilson Lewis Mandala ${ }^{1 *}$ and Michael K. P. Liu $^{2 *}$ \\ ${ }^{1}$ Academy of Medical Sciences, Malawi University of Science and Technology (MUST), Thyolo, Malawi, ${ }^{2}$ Centre for \\ Immunology and Vaccinology, Department of Infectious Disease, Imperial College London, London, United Kingdom
}

Since its emergence in 2019 SARS-CoV-2 has proven to have a higher level of morbidity and mortality compared to the other prevailing coronaviruses. Although initially most African countries were spared from the devastating effect of SARS-CoV-2, at present almost every country has been affected. Although no association has been established between being HIV-1-infected and being more vulnerable to contracting COVID-19, HIV1-infected individuals have a greater risk of developing severe COVID-19 and of COVID-19 related mortality. The rapid development of the various types of COVID-19 vaccines has gone a long way in mitigating the devastating effects of the virus and has controlled its spread. However, global vaccine deployment has been uneven particularly in Africa. The emergence of SARS-CoV-2 variants, such as Beta and Delta, which seem to show some subtle resistance to the existing vaccines, suggests COVID-19 will still be a high-risk infection for years. In this review we report on the current impact of COVID-19 on HIV-1infected individuals from an immunological perspective and attempt to make a case for prioritising COVID-19 vaccination for those living with HIV-1 in Sub-Saharan Africa (SSA) countries like Malawi as one way of minimising the impact of COVID-19 in these countries.

Keywords: COVID-19, HIV, immunity, vaccine, Sub-Sahara Africa

\section{INTRODUCTION}

Coronaviruses have been in existence since time immemorial and six coronaviruses are known to cause disease in humans $(1,2)$. Four of these human coronaviruses (hCoV), 229E, HKU1, NL63 and OC43, cause infections attributed as the common cold and are endemic in different parts of the world (1). However, the other two have been major health concerns with severe acute respiratory syndrome coronavirus (SARS-CoV) and the Middle East respiratory syndrome coronavirus (MERS-CoV) emerging in 2002 and 2012, respectively (3).

The first case of COVID-19 (coronavirus disease) caused by SARS-CoV-2 was reported to the World Health Organisation (WHO) by the Chinese authorities on 31st December $2019(4,5)$. Since its emergence SARS-CoV-2 has proven to be more lethal than the other hCoV with the WHO declaring it a global pandemic in March 2020 (6, 7). Globally, as of October 2021, there have been over 240 million cases and over 4.8 million deaths $(8,9)$. 
SARS-CoV-2 has however not spread evenly throughout the world with countries like Italy, the UK, the USA, Iran, Brazil and India being the most affected countries (9). A report published in November 2020 showed that SARS-CoV-2 incidences appeared low in most African countries recording less than $4 \%$ of the global cases and deaths but in a background of limited COVID19 testing (10) with African countries conducting the least tests $(8,9)$. Furthermore, as of September 2021, SSA, which has a population of 1.15 billion (about $14 \%$ of the global population) (11), had only received $2 \%$ of the world's COVID-19 vaccine supply with most of the countries not reaching the target of vaccinating $10 \%$ of their population (12). In this review we report on the impact COVID-19 on HIV-1-infected individuals from an immunological perspective. We emphasize the need to prioritise COVID-19 vaccination for HIV-1-infected individuals in order to reduce the burden of COVID-19 upon low-resource countries in SSA such as Malawi.

\section{COVID-19 IN MALAWI AND AFRICA}

The first COVID-19 cases in Malawi were confirmed in April 2020 (13) and these were three cases, one index case and two local transmission cases. As of $17^{\text {th }}$ October 2021, there had been 61,716 confirmed cases and 2,292 deaths $(14,15)$. Of the confirmed cases, the average age was 36 years and $66.9 \%$ were male (14). Among the confirmed COVID-19 deaths, the average age was 56.7 years and $82.5 \%$ were male $(9,14)$. While initial COVID-19 cases were primarily imported, the number of local transmissions surpassed imported cases by July 2020 (14). The lower than expected burden of COVID-19 on the African continent massively contradicted various projections which had been calculated at the onset of the pandemic $(16,17)$. Various theories, ranging from genetics to BCG vaccine administration, lower testing rate compared to other countries, have been proposed to explain the lower than expected burden of the disease on the continent $(18-21)$ but these are yet to be proven.

Although the vast majority of those who get infected with COVID-19 remain asymptomatic or merely manifest mild flulike symptoms, some individuals develop life-threatening severe disease and require hospitalization or long COVID-19 disease $(15,22,23)$. For the original variant first detected in Wuhan, China $(4,5)$, the main risk factor for developing severe COVID19 disease and COVID-19-related mortality was age with those aged 65 years or more being at higher risk (24). Other risk factors included being male, having other underlying conditions such as diabetes, severe asthma, smoking, blood group and obesity (24, 25). However, lately some variants, especially the Delta, are causing disease even amongst the young (26).

Although Malawi as a country has lower rates of COVID-19 infection compared to other African countries, HIV-1/AIDS prevalence is still high. With a population of close to 17 million, the HIV-1 prevalence amongst individuals aged between 15 and 64 years is $10.6 \%(27-29)$. This rate is quite similar to other African countries like South Africa with the national prevalence rate of $12.2 \%$ with approximately 6.4 million living with HIV-1 (30) but lower than that of Eswatini (formerly Swaziland) which is estimated at 26\% (31) (Figure 1).

Recent studies have not established any association between being HIV-1-infected and being more vulnerable to contracting COVID-19 (32), but have shown that being infected with HIV-1 is a risk factor for developing severe COVID-19 and for COVID19-related mortality (33-35). It is not known how many of the cases of COVID-19 and COVID-related deaths in Malawi were people living with HIV-1 (15). Since the pandemic started over 90 vaccine candidates have been developed. Malawi, like most other African countries, started receiving the Vaxzevria/OxfordAstraZeneca vaccine through the COVAX initiative with 360,000 doses delivered in March 2021 with more doses in August 2021 supplemented with doses of the Johnson and Johnson's Jansen vaccine (36). Despite this, by 17th October 2021 only $3.01 \%$ Malawians had been fully vaccinated (12).

\section{IMMUNOLOGY OF COVID-19, VIRUS MUTATION, AND VACCINES}

SARS-CoV-2 gains entry into human cells by binding to the Angiotensin Converting Enzyme 2 (ACE2) receptor, which is expressed by various cells including lung epithelial cells (37). Entry of virus into the body triggers the host immune system starting with the innate immune cells which recognise the molecular patterns associated with the virus (38). Two recent reviews $(39,40)$ provide detailed outlines of the different immune components that are involved in the human response against SARS-CoV-2 infection.

At the innate immune response level, a significant increase of monocytes and macrophages has been observed in individuals infected with SARS-CoV-2 with the macrophages infiltrating the lungs and secreting inflammatory cytokines such as IL-6 and IL$1 \beta$ (41) Infected individuals have also been observed to have a suppressed type 1 IFN response, which is fundamental in the fight against viral infections (41). In contrast, other immune cells such as eosinophils were observed to be much lower than normal in those infected with SARS-CoV-2 (42) whereas mast cells were reported to secrete inflammatory cytokines such as IL-1, IL-6, IL33 and other mediators such as histamine and protease $(43,44)$. Decreased cell counts of natural killer (NK) cells were observed in individuals infected with SARS-CoV-2 and these predominantly expressed an exhaustion phenotype (45). Failure of the innate immune response to eliminate the virus will normally lead to the activation of the adaptive immune system with $\mathrm{T}$ and $\mathrm{B}$ cells involved. The CD4+ and CD8+ T cell responses target all parts of the SARS-CoV-2 proteome with CD4+ T cells dominating the response $(46,47)$.

The severity of COVID-19 patients has been associated with a skewed CD4+ T cell response to cytotoxic CD4+ $\mathrm{T}$ follicular helper (Tfh) cells, reduced regulatory $\mathrm{T}$ cells (48) and a less coordinated CD4+ and CD8+ T cell response (47). In infected individuals B cell subsets were observed to be lower than normal but the actual amount of SARS-CoV-2 specific IgG produced was 

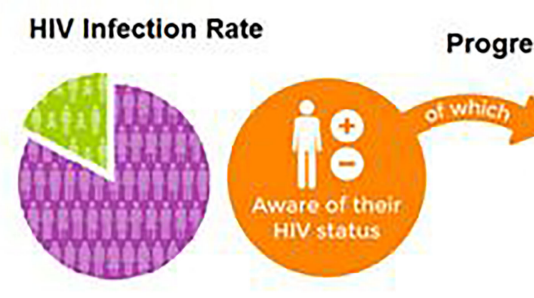

Progress Towards 90-90-90 Targets

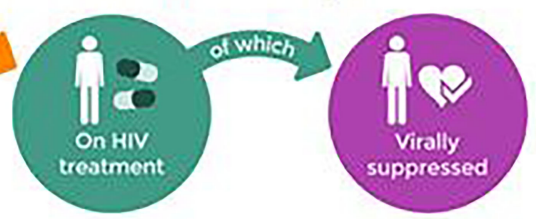

COVID-19 Vaccine Coverage

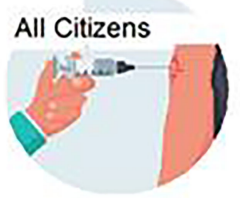

$\begin{array}{lccccc}\text { SE Africa } & 6.70 & 87 & 83 & 90 & 2.00 \\ \text { Malawi } & 10.60 & 90 & 86 & 92 & 2.89 \\ \text { South Africa } & 12.20 & 92 & 75 & 92 & 16.57 \\ \text { Kenya } & 4.50 & 90 & 82 & 92 & 4.08 \\ \text { Uganda } & 5.80 & 89 & 94 & 90 & 2.97 \\ \text { Lesotho } & 22.80 & 93 & 71 & 93 & 8.88 \\ \text { Eswatini } & 26.00 & >95 & >95 & >95 & 11.35 \\ \text { Zambia } & 11.30 & 87 & 89 & 75 & 2.23 \\ \text { Zimbabwe } & 12.80 & 90 & 94 & 86 & 18.85 \\ \text { Botswana } & 20.70 & 92 & 89 & 995 & 16.35 \\ \text { Tanzania } & 4.80 & 83 & 90 & 92 & 0.80\end{array}$

FIGURE 1 | Progress made by various countries in the Sub-Saharan Africa towards achieving the 90-90-90 Targets as of 2020 (70) and COVID-19 percentage coverage for individuals who had been fully vaccinated, regardless of HIV status, in each country as of September 2021 (71).

high (49). Antibodies are thought to be protective with convalescent plasma and neutralizing monoclonal antibodies used as treatment for COVID-19 patients $(50,51)$. However, the antibody titre levels against the receptor binding domain and anti-spike neutralizing antibodies were reportedly higher in more severely affected patients compared to mildly ill patients (52). This may also be a consequence of prolonged infection.

$>$ The efficacy levels reported for each vaccine type are those observed against the original strain of SARS-CoV-2 initially detected in Wuhan, China. However, since then several different variants of the virus have emerged (53). The Alpha variant, first documented in the UK in September 2020, became dominant, but has now been superseded by the Delta variant that emerged from India in October 2020 (53). Other variants of concern (VOC) are the Beta variant and the Gamma variant (53). The emergence of these new variants has questioned whether the various COVID-19 vaccines currently in use would maintain their efficacies.

One recent study reported reduced efficacy of the Pfizer vaccine against the Alpha and Beta variants (54) with others hypothesizing that some of the vaccines will drastically lose their efficacy against the new variants (55). The clinically approved human monoclonal antibody treatments, bamlanivimab and etesevimab, were unable to neutralize the Beta variant (56). Furthermore, both the Beta and Delta variants were more resistant to neutralization to sera from Moderna/Spikevax, Comirnaty/Pfizer-BioNTech and Vaxzevria/Oxford-Astra Zeneca vaccines than the Alpha variant (57).

One of the main concerns with the COVID-19 vaccines has been whether their efficacy could be affected when administered to HIV1-infected individuals due to their immunocompromised status (58). However, results of two recent studies investigating the efficacy of the AstraZeneca COVID-19 vaccine in the UK and South Africa reported that there were no differences in terms of vaccine-related antibody or T cell-mediated responses between HIV-1-infected participants and HIV-1-negative controls at any stage of the vaccination process $(58,59)$. The studies also showed that antibody responses were not affected by the CD4 $\mathrm{T}$ cell count in the HIV-1-infected individuals $(58,59)$. Similar results were 
reported by a group working on a nanoparticle vaccine, Novavax, although the researchers still propose that more work needs to be done in HIV-1-infected individuals with CD4 T cell counts lower than 350 cells/ $\mu$ l blood and with detectable viral loads (60).

\section{HIV-1 AND IMMUNE DYSFUNCTION}

It has been shown that years of untreated HIV-1 infection before commencing combination antiretroviral treatment (cART) can substantially affect the length of time the immune system needs to fully recover (61). Thus, it is beneficial for HIV-1+ patients to start cART as early as possible (62). An environment of activation, dysfunction and inflammation pervades the immune system during untreated HIV-1 infection. Chronic immune activation of $\mathrm{T}$ cells occurs through persistent depletion and expansion of $\mathrm{T}$ cells accompanied with overexpression of CD38 and HLA-DR (62). In B cells there is an over-production of autoantibodies, increased expression of activation markers but also dysfunctional responses to $\mathrm{T}$ cell help and a loss of memory B cells (63). The innate immune system shows raised levels of IL-1, IL-6, TNF and C-reactive protein (CRP) amongst other things (62). Meanwhile CD4+ Tfh cells are expanded in untreated HIV-1, which leads to changes in certain B cell populations, an increase of germinal B cells, fewer memory B cells and more BCL6 transcriptional repressor (64).

Furthermore, B cell vaccine responses to influenza, HPV and yellow fever are attenuated in HIV-1 patients (65-67). During HIV1 infection, there is also loss of the mucosal barrier leading to microbial translocation demonstrated through the increased levels of soluble CD14 and soluble CD163 (62). This drives activation of the innate immune system, such as macrophages along with abnormally raised levels of pro-inflammatory cytokines such as IFN- $\alpha$, TNF- $\alpha$, IL-1, IL-6 and IL-18 (62). One of the roles of plasmacytoid DCs (pDC) is to produce IFN- $\alpha$ and IFN- $\beta$ during early stages of a viral infection. Unfortunately, HIV-1 infection impairs the function of pDC and reduces their frequency (68).

The introduction of CART in the late nineties has had a major impact on the lives of millions of HIV-1+ patients increasing life expectancy to non-infected levels. However, depending largely on the CD4+ T cell count before cART commencement (61), full immune restoration is not always attained such that as many as $16 \%$ may not attain CD4+ T cell counts greater than 200 cells $/ \mu 1$ blood after four years of treatment (69).

According to UNAIDS, $83 \%$ (with a range of $60-92 \%$ ) of HIV-1-infected individuals in eastern and southern Africa had access to cART in 2020 (70). For Malawi, it was estimated that $88 \%$ had access to cART and $92 \%$ had suppressed viral loads. The respective percentages for some selected SSA countries are presented in Figure 1. Based on these figures, it is clear that a significant population of $\mathrm{HIV}-1+$ patients in SSA are potentially vulnerable to further HIV-1 associated opportunistic infections and other pathogens such as SARS-CoV-2.

While cART does have an effect on reducing $\mathrm{T}$ cell activation, it does not completely abolish all chronic immune activation as there are still elevated levels of IL-6, CRP, D-dimer and
sCD14 (72). The frequency of Tfh cells drops to normal levels under cART but there is an over-representation of germinal centre B cells and an under-representation of memory B cells (72). Meanwhile, the innate immune functionality of $\mathrm{pDC}$ remains affected in patients on CART, which may compromise the anti-viral response (68). Myeloid dendritic cells frequencies appear normal before and during cART but their ability to skew towards to Th1 responses is impaired (73).

Hearps and colleagues showed that monocytes have impaired phagocytic activity in cART patients and they resemble those of elderly HIV-1-negative subjects (74).

Natural killer (NK) cells play a major role against viral pathogens producing IFN- $\gamma$ and killing virally-infected cells through antibody-dependent cellular cytotoxicity (ADCC). However, in HIV-1+ patients their ability to performed ADCC is compromised and persists under cART (75). Therefore, all these factors may affect the ability of $\mathrm{HIV}-1+$ patients to respond to further viral infections including SARS-CoV-2 especially if the CD4+ $\mathrm{T}$ cell counts of the affected individuals have not yet "normalized" in the course of being on cART.

Specifically, if plasma levels of IL-6 are already elevated in cART patients, some have speculated that such individuals would be more likely to get more severe symptoms of COVID19 (76). One of the major risk factors of mortality in COVID-19 is age (24) and it has been suggested that many of the immunocellular disturbances associated with HIV-1 infection have similarities with immune systems in the elderly (77). The hallmarks of immune systems in the elderly consist of declining frequencies of naive $\mathrm{T}$ cells and hematopoietic progenitor cells with heightened levels of inflammation, which all have parallels with HIV-1 affected immune systems (77).

Although, multiple factors contribute to pathology associated with COVID-19, an aged immune system because of a HIV-1 infection may not be beneficial. Currently, several developed countries are already administering COVID-19 vaccine booster shots to individuals aged 65 years and above and those who are immunocompromised (78). Considering the similarities of the immune systems, comparable requirements might also be essential for HIV-1-infected patients.

\section{COVID-19 IN HIV-1-INFECTED INDIVIDUALS}

As mentioned earlier, no study so far has established any link between being HIV-1-infected and being more vulnerable to contracting COVID-19 (32). What is known though is that being infected with HIV-1 is a risk factor for developing severe COVID-19 (79) and for COVID-19 related mortality (33-35). Furthermore, a recent case report in South Africa revealed the development of over ten new SARS-CoV-2 variants in one individual who presented with untreated HIV-1 infection and had been co-infected with SARS-CoV-2 (80). The authors proposed that untreated HIV-1 infection might provide a fertile environment that favours intra-host mutation of SARSCoV-2 (80). 
With a seemingly waning efficacy of the current vaccines against some of the SARS-CoV-2 variants (54-57), a scenario whereby the current vaccines become ineffectual with time is a real possibility. The recent reports of individuals who had been infected with two different SARS-CoV-2 variants (81-83) suggest that it is possible for some individuals to be concurrently infected by more than one variant of SARS-CoV-2 and subsequently more virulent variants could emerge through recombination (84). With COVID-19 vaccines proving to be just as effective in HIV-1-infected individuals, prioritising inoculation of this group might be one of the ways of mitigating variant development. The WHO provides guidelines on the prioritization of vaccine administration if supplies are limited (85). The potential risk of intra-host mutation development in HIV-1-infected individuals reported in South Africa (80) may serve as an additional justification for the WHO to move this population group further up the COVID-19 vaccination priority list. If this observation is repeated in other studies involving both untreated and treated HIV-1-infected individuals in countries where HIV/AIDS prevalence is high, countries might wish to prioritise all HIV-1-infected individuals to be vaccinated against SARS-CoV-2 in order to keep the variants development in check.

\section{CHALLENGES AHEAD}

As long as there is significant community transmission taking place, the virus will continue to mutate and variants emerge (84). One such variant, C.1.2, was first detected in May 2021 in Mpumalanga South Africa and by August 2021 it had spread to various provinces in the country (84). Although much about the C.1.2 variant in terms of virulence and transmissibility is yet to be fully elucidated, its discovery emphasises the point that in countries where a good proportion of the population is unvaccinated, VOCs will continue to arise posing a threat to the world at large. As it has been shown with the Delta variant, the efficacy of the current COVID-19 vaccines against the new variants tends to be compromised (54, 55). In the event that a new variant emerges on the global scene, which is completely resistant to all current vaccines, it would derail the fight against SARS-CoV-2 and downgrade the gains so far attained. As more countries gradually but cautiously lift travel bans from high-risk countries, the risk of new vaccine-resistant variants spreading to different parts of the world remains high (86).

Of major concern is the recently observed disparity in vaccine coverage between developed countries, which have already attained over $75 \%$ vaccine coverage, and most African countries (Figure 1) which, on average, have only achieved $2 \%$ coverage (87). This socalled "vaccine apartheid" phenomenon could be exacerbated if the

\section{REFERENCES}

1. van der Hoek L. Human Coronaviruses: What do They Cause? Antivir Ther (2007) 12(4 Pt B):651-8. doi: 10.1177/135965350701200S01.1

2. Lau SK, Woo PC, Yip CC, Tse H, Tsoi HW, Cheng VC, et al. Coronavirus HKU1 and Other Coronavirus Infections in Hong Kong. J Clin Microbiol (2006) 44(6):2063-71. doi: 10.1128/JCM.02614-05 current trend of more developed countries proceeding with the implementation of proposed "booster" or third jab $(88,89)$. These vaccines could have been more beneficial, and more effective against the pandemic, if administered either as first or second jabs in developing countries. The recent report by WHO (90) on some developed countries having even a greater access towards the vaccines originally meant for developing countries under the COVAX initiative makes this scenario even worse. Meanwhile the ensuing low COVID-19 vaccination coverage in Africa (71) still provides a potentially conducive environment for the development of new SARS-CoV-2 variants.

While it is clear that the majority of unvaccinated individuals survive primary infection without the need for hospitalization (91) what remains to be fully elucidated are the specific immune correlates of protection against SARS-CoV-2 (92-94). The pandemic will continue until further studies reveal the veritable correlates of protection against SARS-CoV-2 and/or the whole world is immunized, including those most vulnerable to severe COVID-19 such as those living with HIV-1. Waning vaccine-induced antibodies (95) and emerging new variants (54, $55,79)$ will inadvertently prolong the period during which vaccine booster jabs and vaccines against VOC will be required.

The introduction of the Extended Program on Immunization (EPI) by WHO back in 1974 has been one of the success stories in the region (96). Given, the necessary support, SSA countries are capable of contributing substantially to the global fight against COVID-19.

\section{AUTHOR CONTRIBUTIONS}

Both authors contributed equally to this work in writing, reviewing, and editing.

\section{FUNDING}

WM is funded by the Malawi University of Science and Technology and ML is currently funded by the Wellcome Trust [Grant Number: P86433].

\section{ACKNOWLEDGMENTS}

We are grateful to Dr. Nesrina Imami, Reader in Immunology in the Faculty of Medicine, Department of Infectious Diseases, Imperial College London, for reviewing the original draft of the manuscript.

3. de Wit E, van Doremalen N, Falzarano D, Munster VJ. SARS and MERS: Recent Insights Into Emerging Coronaviruses. Nat Rev Microbiol (2016) 14 (8):523-34. doi: 10.1038/nrmicro.2016.81

4. Zhu N, Zhang D, Wang W, Li X, Yang B, Song J, et al. China Novel Coronavirus Investigating and Research Team. A Novel Coronavirus From Patients With Pneumonia in China, 2019. N. Engl J Med (2020) 382:727-33. doi: 10.1056/NEJMoa2001017 
5. Gralinski LE, Menachery VD. Return of the Coronavirus: 2019-Ncov. Viruses (2020) 12(2):135. doi: 10.3390/v12020135

6. Weston S, Frieman MB. COVID-19: Knowns, Unknowns, and Questions. mSphere (2020) 18:5(2):e00203-20. doi: 10.1128/mSphere.00203-20

7. WHO Director-General's Opening Remarks at the Media Briefing on COVID19-11 March 2020 . Available at: https://www.who.int/director-general/ speeches/detail/who-director-general-s-opening-remarks-at-the-mediabriefing-on-covid-19-11-march-2020 (Accessed on 13th October 2021).

8. World Health Organization. Novel Coronavirus (COVID-19) Situation. Available at: https://www.who.int/emergencies/diseases/novel-coronavirus2019 (Accessed on 13th October 2021).

9. Dong E, Du H, Gardner L. An Interactive Web-Based Dashboard to Track COVID-19 in Real Time. Lancet Infect Dis (2020) 20:533-4. doi: 10.1016/ S1473-3099(20)30120-1

10. Maeda JM, Nkengasong JN. The Puzzle of the COVID-19 Pandemic in Africa. Science (2021) 371(6524):27-8. doi: 10.1126/science.abf8832

11. The World Bank. Sub-Saharan Africa Population. Available at: https://data. worldbank.org/indicator/SP.POP.TOTL?locations=ZG (Accessed on 22nd October 2021).

12. World Health Organization. Fifteen African Countries Hit 10\% COVID-19 Vaccination Goal. Available at: https://www.afro.who.int/news/fifteenafrican-countries-hit-10-covid-19-vaccination-goal (Accessed on 30th September 2021).

13. United Nations Malawi. COVID-19 Update Malawi Highlights, 2020. Available at: https://malawi.un.org/en/106836-malawi-covid-19-situationupdate-no34-31-dec-2020 (Accessed on 13th October 2021).

14. Public Health Institute of Malawi. COVID-19 Daily Situation Report, 2020. Available at: https://www.humanitarianresponse.info/en/operations/malawi/ document/public-health-institute-malawi-covid-19-update-15-21-march2021 (Accessed on 13th October 2021).

15. Malawi Ministry Of Health. COVID-19 National Information Dashboard, 2020 . Available at: https://covid19.health.gov.mw/ (Accessed on 8th September 2021).

16. El-Sadr WM, Justman J. Africa in the Path of Covid-19. N Engl J Med (2020) 16:383(3):e11. doi: 10.1056/NEJMp2008193

17. Nkengasong JN, Mankoula W. Looming Threat of COVID-19 Infection in Africa: Act Collectively, and Fast. Lancet (2020) 395(10227):841-2. doi: 10.1016/S0140-6736(20)30464-5

18. Mbow M, Lell B, Jochems SP, Cisse B, Mboup S, Dewals BG, et al. COVID-19 in Africa: Dampening the Storm? Science (2020) 369(6504):624-6. doi: $10.1126 /$ science.abd3902

19. Diop BZ, Ngom M, Pougué Biyong C, Pougué Biyong JN. The Relatively Young and Rural Population may Limit the Spread and Severity of COVID-19 in Africa: A Modelling Study. BMJ Global Health (2020) 5:e002699. doi: 10.1136/bmjgh-2020-002699

20. Njenga MK, Dawa J, Nanyingi M, Gachohi J, Ngere I, Letko M, et al. Why is There Low Morbidity and Mortality of COVID-19 in Africa? Am J Trop Med Hyg (2020) 103(2):564-9. doi: 10.4269/ajtmh.20-0474

21. Curtis N, Sparrow A, Ghebreyesus TA, Netea MG. Considering BCG Vaccination to Reduce the Impact of COVID-19. Lancet (2020) 395 (10236):1545-6. doi: 10.1016/S0140-6736(20)31025-4

22. Lauer SA, Grantz KH, Bi Q, Jones FK, Zheng Q, Meredith HR, et al. The Incubation Period of Coronavirus Disease 2019 (COVID-19) From Publicly Reported Confirmed Cases: Estimation and Application. Ann Intern Med (2020) 172(9):577-82. doi: 10.7326/M20-0504

23. Grant MC, Geoghegan L, Arbyn M, Mohammed Z, McGuinness L, Clarke EL, et al. The Prevalence of Symptoms in 24,410 Adults Infected by the Novel Coronavirus (SARS-CoV-2; COVID-19): A Systematic Review and MetaAnalysis of 148 Studies From 9 Countries. PloS One (2020) 15(6):e0234765. doi: 10.1371/journal.pone.0234765

24. Williamson EJ, Walker AJ, Bhaskaran K, Bacon S, Bates C, Morton CE, et al. Factors Associated With COVID-19-Related Death Using OpenSAFELY. Nature (2020) 584(7821):430-6. doi: 10.1038/s41586-0202521-4

25. Booth A, Reed AB, Ponzo S, Yassaee A, Aral M, Plans D, et al. Population Risk Factors for Severe Disease and Mortality in COVID-19: A Global Systematic Review and Meta-Analysis. PloS One (2021) 16(3):e0247461. doi: 10.1371/ journal.pone.0247461/2021.10.06.21264467
26. Erika M, Sudre CH, Canas LS, Bhopal SS, Hughes RC, Chen L, et al. Illness Characteristics of COVID-19 in Children Infected With the SARS-CoV-2 Delta Variant. medRxiv (2021) 10(06):21264467.

27. Country Progress Report-Malawi. Global AIDS Monitoring 2018. Available at: https://www.unaids.org/sites/default/files/country/documents/MWI_2018_ countryreport.pdf (Accessed on 13th October 2021).

28. The Malawi National Strategic Plan for HIV and Aids (2015-2020). Available at: https://www.childrenandaids.org/node/445 (Accessed on 8th September 2021).

29. Nutor JJ, Duah HO, Agbadi P, Duodu PA, Gondwe KW. Spatial Analysis of Factors Associated With HIV Infection in Malawi: Indicators for Effective Prevention. BMC Public Health (2020) 20:1167. doi: 10.1186/s12889-02009278-0

30. Mabaso M, Makola L, Naidoo I, Mlangeni LL, Jooste S, Simbayi L. HIV Prevalence in South Africa Through Gender and Racial Lenses: Results From the 2012 Population-Based National Household Survey. Int J Equity Health (2019) 18:167. doi: 10.1186/s12939-019-1055-6

31. Belle JA, Gamedze NN. Behavioral Factors Contributing to the Transmission of HIV and AIDS Amongst Young Women of Mbabane in Swaziland. Afr Health Sci (2019) 19(3):2302-11. doi: 10.4314/ahs.v19i3.2

32. Drain PK, Garrett N. SARS-CoV-2 Pandemic Expanding in Sub-Saharan Africa: Considerations for COVID-19 in People Living With HIV. EClinicalMedicine (2020) 22:100342. doi: 10.1016/j.eclinm.2020.100342

33. Bhaskaran K, Rentsch CT, MacKenna B, Schultze A, Mehrkar A, Bates CJ, et al. HIV Infection and COVID-19 Death: A Population-Based Cohort Analysis of UK Primary Care Data and Linked National Death Registrations Within the OpenSAFELY Platform. Lancet HIV (2021) 8(1): e24-32. doi: 10.1016/S2352-3018(20)30305-2

34. Ssentongo P, Heilbrunn ES, Ssentongo AE, Advani S, Chinchilli VM, Nunez JJ, et al. Epidemiology and Outcomes of COVID-19 in HIV-Infected Individuals: A Systematic Review and Meta-Analysis. Sci Rep (2021) 11 (1):6283. doi: 10.1038/s41598-021-85359-3

35. Cabello A, Zamarro B, Nistal S, Victor V, Hernández J, Prieto-Pérez L, et al. COVID-19 in People Living With HIV: A Multicenter Case-Series Study. Int $J$ Infect Dis (2021) 102:310-5. doi: 10.1016/j.ijid.2020.10.060

36. UNICEF; Malawi COVID-19 Situation Report . Available at: https://www. unicef.org/malawi/reports/unicef-malawi-covid-19-situation-report-10august (Accessed on September 27th 2021).

37. Zhang X, Li S, Niu S. ACE2 and COVID-19 and the Resulting ARDS. Postgrad Med J (2020) 96(1137):403-7. doi: 10.1136/postgradmedj-2020-137935

38. Azkur AK, Akdis M, Azkur D, Sokolowska M, van de Veen W, Brüggen MC, et al. Immune Response to SARS-CoV-2 and Mechanisms of Immunopathological Changes in COVID-19. Allergy (2020) 75(7):1564-81. doi: 10.1111/all.14364

39. Bhardwaj A, Sapra L, Saini C, Azam Z, Mishra PK, Verma B, et al. COVID-19: Immunology, Immunopathogenesis and Potential Therapies. Int Rev Immunol (2021) 27:1-36. doi: 10.1080/08830185.2021.1883600

40. Sokolowska M, Lukasik ZM, Agache I, Akdis CA, Akdis D, Akdis M, et al. Immunology of COVID-19: Mechanisms, Clinical Outcome, Diagnostics, and Perspectives-A Report of the European Academy of Allergy and Clinical Immunology (EAACI). Allergy (2020) 75(10):2445-76. doi: 10.1111/all.14462

41. Pelaia C, Tinello C, Vatrella A, De Sarro G, Pelaia G. Lung Under Attack by COVID-19-Induced Cytokine Storm: Pathogenic Mechanisms and Therapeutic Implications. Ther Adv Respir Dis (2020) 14:1-9. doi: 10.1177/ 1753466620933508

42. Liu F, Xu A, Zhang Y, Xuan W, Yan T, Pan K, et al. Patients of COVID-19 may Benefit From Sustained Lopinavir-Combined Regimen and the Increase of Eosinophil may Predict the Outcome of COVID-19 Progression. Int J Infect Dis (2020) 95:183-91. doi: 10.1016/j.ijid.2020.03.013

43. Kritas SK, Ronconi G, Caraffa A, Gallenga CE, Ross R, Conti P. Mast Cells Contribute to Coronavirus-Induced Inflammation: New Anti-Inflammatory Strategy. J Biol Regul Homeost Agents (2020) 34(1):9-14. doi: 10.23812/20Editorial-Kritas

44. Ronconi G, Teté G, Kritas SK, Gallenga CE, Caraffa AL, Ross R, et al. SARSCoV-2, Which Induces COVID-19, Causes Kawasaki-Like Disease in Children: Role of Pro-Inflammatory and Anti-Inflammatory Cytokines. J Biol Regul Homeost Agents (2020) 34(3):767-73. doi: 10.23812/ EDITORIAL-RONCONI-E-59 
45. Zheng M, Gao Y, Wang G, Song G, Liu S, Sun D, et al. Functional Exhaustion of Antiviral Lymphocytes in COVID-19 Patients. Cell Mol Immunol (2020) 17:533-5. doi: 10.1038/s41423-020-0402-2

46. Grifoni A, Weiskopf D, Ramirez SI, Mateus J, Dan JM, Rydyznski C, et al. Targets of T Cell Responses to SARS-CoV-2 Coronavirus in Humans With COVID-19 Disease and Unexposed Individuals. Cell (2020) 181:14891501.e15. doi: 10.1016/j.cell.2020.05.015

47. Peng Y, Mentzer AJ, Liu G, Yao X, Yin Z, Dong D, et al. Broad and Strong Memory CD4+ and CD8+ T Cells Induced by SARS-CoV-2 in UK Convalescent Individuals Following COVID-19. Nat Immunol (2020) 21:1336-45. doi: 10.1038/s41590-020-0782-6

48. Meckiff BJ, Ramírez-Suástegui C, Fajardo V, Chee SJ, Kusnadi A, Hayley Simon $\mathrm{H}$, et al. Imbalance of Regulatory and Cytotoxic SARS-CoV-2-Reactive CD4+ T Cells in COVID-19. Cell (2020) 183:1340-1353.e16. doi: 10.1016/ j.cell.2020.10.001

49. Moderbacher CR, Ramirez SI, Dan JM, Grifoni A, Hastie KM, Weiskopf D, et al. Antigen-Specific Adaptive Immunity to SARS-CoV-2 in Acute COVID19 and Associations With Age and Disease Severity. Cell (2020) 183:9961012.e19. doi: 10.1016/j.cell.2020.09.038

50. Ju B, Zhang Q, Ge J, Wang R, Sun J, Ge X, et al. Human Neutralizing Antibodies Elicited by SARS-CoV-2 Infection. Nature (2020) 584(7819):1159. doi: 10.1038/s41586-020-2380-Z

51. Libster R, Pérez Marc G, Wappner D, Coviello S, Bianchi A, Braem V, et al. Fundación INFANT-COVID-19 Group. Early High-Titer Plasma Therapy to Prevent Severe Covid-19 in Older Adults. N Engl J Med (2021) 384(7):610-8. doi: 10.1056/NEJMoa2033700

52. Taylor PC, Adams AC, Hufford MM, de la Torre I, Winthrop K, Gottlieb RL. Neutralizing Monoclonal Antibodies for Treatment of COVID-19. Nat Rev Immunol (2021) 21:382-93. doi: 10.1038/s41577-021-00542-x

53. European Centre for Disease Prevention and Control: SARS-CoV-2 Variants of Concern as of 7 October 2021 . Available at: https://www.ecdc.europa.eu/en/ covid-19/variants-concern (Accessed on 13th October 2021).

54. Abu-Raddad LJ, Chemaitelly H, Butt AANational Study Group for COVID-19 Vaccination. Effectiveness of the BNT162b2 Covid-19 Vaccine Against the B.1.1.7 and B.1.351 Variants. N Engl J Med (2021) 385(2):187-9. doi: 10.1056/ NEJMc2104974

55. Rubin R. COVID-19 Vaccines vs Variants-Determining How Much Immunity Is Enough. JAMA (2021) 325(13):1241-3. doi: 10.1001/ jama.2021.3370

56. Wang P, Nair MS, Liu L, Iketani S, Luo Y, Guo Y, et al. Antibody Resistance of SARS-CoV-2 Variants B.1.351 and B.1.1.7. Nature (2021) 593:130-5. doi: 10.1038/s41586-021-03398-2

57. Planas D, Veyer D, Baidaliuk A, Staropoli I, Guivel-Benhassine F, Rajah MM, et al. Reduced Sensitivity of SARS-CoV-2 Variant Delta to Antibody Neutralization. Nature (2021) 596(7871):276-80. doi: 10.1038/s41586-02103777-9

58. Frater J, Ewer KJ, Ogbe A, Pace M, Adele S, Adland E, et al. Safety and Immunogenicity of the ChAdOx1 Ncov-19 (AZD1222) Vaccine Against SARS-CoV-2 in HIV Infection: A Single-Arm Substudy of a Phase 2/3 Clinical Trial. Lancet HIV (2021) 8(8):E474-85. doi: 10.1016/S2352-3018 (21)00103-X

59. Madhi SA, Ballie V, Cutland CL, Voysey M, Koen AL, Fairlie L, et al. Safety and Efficacy of the ChAdOx1 Ncov-19 (AZD1222) Covid-19 Vaccine Against the B.1.351 Variant in South Africa. N Engl J Med (2021) 384(20):1885-98. doi: 10.1056/NEJMoa2102214

60. Shinde V, Bhikha S, Hoosain Z, Archary M, Bhorat Q, Fairlie L, et al. Efficacy of NVX-CoV2373 Covid-19 Vaccine Against the B.1.351 Variant. N Engl J Med (2021) 384(20):1899-909. doi: 10.1056/NEJMoa2103055

61. Le T, Wright EJ, Smith DM, He W, Catano G, Okulicz JF, et al. Enhanced CD4 + T-Cell Recovery With Earlier HIV-1 Antiretroviral Therapy. N Engl J Med (2013) 368:218-30. doi: 10.1056/NEJMoa1110187

62. Klatt NR, Chomont N, Douek DC, Deeks SG. Immune Activation and HIV Persistence: Implications for Curative Approaches to HIV Infection. Immunol Rev (2013) 254:326-42. doi: 10.1111/imr.12065

63. Moir S, Ogwaro KM, Malaspina A, Vasquez J, Donoghue ET, Hallahan CW, et al. Perturbations in B Cell Responsiveness to CD4+ T Cell Help in HIVInfected Individuals. Proc Natl Acad Sci USA (2003) 200:6057-62. doi: $10.1073 /$ pnas. 0730819100
64. Lindqvist M, van Lunzen J, Soghoian DZ, Kuhl BD, Ranasinghe S, Kranias G, et al. Expansion of HIV-Specific T Follicular Helper Cells in Chronic HIV Infection. J Clin Invest (2012) 122(9):3271-80. doi: 10.1172/JCI64314

65. Malaspina A, Moir S, Orsega SM, Vasquez J, Miller NJ, Donoghue ET, et al. Compromised B Cell Responses to Influenza Vaccination in HIV-Infected Individuals. J Infect Dis (2005) 191(9):1442-50. doi: 10.1086/429298

66. Avelino-Silva VI, Miyaji KT, Mathias A, Costa DA, de Carvalho Dias JZ, Lima SB, et al. CD4/CD8 Ratio Predicts Yellow Fever Vaccine-Induced Antibody Titers in Virologically Suppressed HIV-Infected Patients. J Acquir Immune Defic Syndr (2016) 71(2):189-95. doi: 10.1097/QAI.0000000000000845

67. Fuster F, Vargas JI, Jensen D, Sarmiento V, Acuña P, Peirano F, et al. CD4/ CD8 Ratio as a Predictor of the Response to HBV Vaccination in HIVPositive Patients: A Prospective Cohort Study. Vaccine (2016) 34(16):1889_ 95. doi: 10.1016/j.vaccine.2016.02.055

68. Chehimi J, Campbell D, Azzoni L, Bacheller D, Papasavvas E, Jerandi G, et al Persistent Decreases in Blood Plasmacytoid Dendritic Cell Number and Function Despite Effective Highly Active Antiretroviral Therapy and Increased Blood Myeloid Dendritic Cells in HIV-Infected Individuals. J Immunol (2002) 168:4796-801. doi: 10.4049/jimmunol.168.9.4796

69. Kaufmann GR, Perrin L, Pantaleo G, Opravil M, Furrer H, Telenti A, et al. CD4 T-Lymphocyte Recovery in Individuals With Advanced HIV-1 Infection Receiving Potent Antiretroviral Therapy for 4 Years: The Swiss HIV Cohort Study. Arch Intern Med (2003) 163(18):2187-95. doi: 10.1001/archinte.163. 18.2187

70. UNAIDS Report on East and Southern Africa . Available at: https://www. unaids.org/en/regionscountries/easternandsouthernafrica (Accessed on 14th October 2021).

71. COVID-19 Vaccination: Latest Updates From Africa CDC on Progress Made in COVID-19 Vaccinations on the Continent . Available at: https://africacdc.org/ covid-19-vaccination/ (Accessed on 8th September 2021).

72. Wilson EMP, Sereti I. Immune Restoration After Antiretroviral Therapy: The Pitfalls of Hasty or Incomplete Repairs. Immunol Rev (2013) 254:343-54. doi: 10.1111/imr.12064

73. Miller EA, Spadaccia MR, O’Brien MP, Rolnitzky L, Sabado R, Manches O, et al. Plasma Factors During Chronic HIV-1 Infection Impair IL-12 Secretion by Myeloid Dendritic Cells via a Virus-Independent Pathway. J Acquir Immune Defic Syndr (2012) 61:535-44. doi: 10.1097/QAI.0b013e31826afbce

74. Hearps AC, Maisa A, Cheng W-J, Angelovich TA, Lichtfuss GF, Palmer CS, et al. HIV Infection Induces Age-Related Changes to Monocytes and Innate Immune Activation in Young Men That Persist Despite Combination Antiretroviral Therapy. AIDS (2012) 26(7):843-53. doi: 10.1097/ QAD.0b013e328351f756

75. Lichtfuss GF, Cheng W-J, Farsakoglu Y, Paukovics G, Rajasuriar R, Velayudham P, et al. Virologically Suppressed HIV Patients Show Activation of NK Cells and Persistent Innate Immune Activation. J Immunol (2012) 189:1491-9. doi: 10.4049/jimmunol.1200458

76. Santa Cruz A, Mendes-Frias A, Isabel OA, Luís D, Rita MA, Alexandre C, et al. Interleukin-6 Is a Biomarker for the Development of Fatal Severe Acute Respiratory Syndrome Coronavirus 2 Pneumonia. Front Immunol (2021) 12:613422. doi: 10.3389/fimmu.2021.613422

77. Appay V, Saucea D. Assessing Immune Aging in HIV-Infected Patients. Virulence (2017) 8(5):529-38. doi: 10.1080/21505594.2016.1195536

78. Griffin S. Covid-19: Millions Could be Offered Booster Vaccinations From September. BMJ (2021) 374:n1686. doi: 10.1136/bmj.n1686

79. Karim F, Gazy I, Cele S, Zungu Y, Krause R, Bernstein M, et al. HIV Status Alters Disease Severity and Immune Cell Responses in Beta Variant SARSCoV-2 Infection Wave. Elife (2021) 10:e67397.

80. Karim F, Moosa MYS, Gosnell BI, Cele S, Giandhari J, Pillay S, et al. Persistent SARS-CoV-2 Infection and Intra-Host Evolution in Association With Advanced HIV Infection. medRxiv (2021) 06(03):21258228. doi: 10.1101/ 2021.06.03.21258228

81. Pedro N, Silva CN, Magalhães AC, Cavadas B, Rocha AM, Moreira AC, et al. Dynamics of a Dual SARS-CoV-2 Lineage Co-Infection on a Prolonged Viral Shedding COVID-19 Case: Insights Into Clinical Severity and Disease Duration. Microorganisms (2021) 9(2):300. doi: 10.3390/microorganisms 9020300

82. Francisco RDSJr, Benites LF, Lamarca AP, de Almeida LGP, Hansen AW, Gularte JS, et al. Pervasive Transmission of E484K and Emergence of VUI 
NP13L With Evidence of SARS-CoV-2 Co-Infection Events by Two Different Lineages in Rio Grande do Sul, Brazil. Virus Res (2021) 296:198345. doi: 10.1016/j.virusres.2021.198345

83. Vankeerberghen A, Holderbeke A, Boel A, Van Vaerenbergh K, De Beenhouwer $\mathrm{H}$, Cattoir L, et al. A 90 Year Woman was Infected by Two SARS-CoV-2 Variants in March 2021. Aalst, Belgium: Proceedings of the 2021 European Congress on Clinical Microbiology \& Infectious Diseases (2021).

84. Scheepers C, Everatt J, Amoako D, Mnguni A, Ismail A, Mahlangu B, et al. The Continuous Evolution of SARS-CoV-2 in South Africa: A New Lineage With Rapid Accumulation of Mutations of Concern and Global Detection. medRxiv (2021) 08(20):21262342. doi: 10.1101/2021.08.20.21262342

85. WHO SAGE Roadmap For Prioritizing Uses Of COVID-19 Vaccines In The Context Of Limited Supply. Available at: https://www.who.int/ publications/i/item/who-sage-roadmap-for-prioritizing-uses-of-covid-19vaccines-in-the-context-of-limited-supply (Accessed on 27th September 2021).

86. Chinazzi M, Davis J, Ajelli M, Gioannini C, Litvinova M, Merler S, et al. The Effect of Travel Restrictions on the Spread of the 2019 Novel Coronavirus (COVID-19) Outbreak. Science (2020) 368(6489):395-400. doi: 10.1126/ science.aba9757

87. Hassan F, Yamey G, Abbasi K. Profiteering From Vaccine Inequity: A Crime Against Humanity? BMJ (2021) 374:n2027. doi: 10.1136/bmj.n2027

88. Flaxman A, Marchevsky NG, Jenkin D, Aboagye J, Aley PK, Angus B, et al. Reactogenicity and Immunogenicity After a Late Second Dose or a Third Dose of ChAdOx1 Ncov-19 in the UK: A Substudy of Two Randomised Controlled Trials (COV001 and COV002). Lancet (2021) 398 (10304):981-90. doi: 10.1016/S0140-6736(21)01699-8

89. Mahase E. Covid-19: Booster Dose Reduces Infections and Severe Illness in Over 60s, Israeli Study Reports. BMJ (2021) 374:n2297. doi: 10.1136/ bmj.n2297

90. OXFAM International. Pharmaceutical Companies and Rich Nations Delivering Just One in Seven of the Doses Promised for Developing Countries. Available at: https://www.oxfam.org/en/press-releases/ pharmaceutical-companies-and-rich-nations-delivering-just-one-sevendoses-promised (Accessed on 22nd October 2021).

91. Liu B, Jayasundara D, Pye V, Dobbins T, Dore GJ, Matthews G, et al. Whole of Population-Based Cohort Study of Recovery Time From COVID-19 in
New South Wales Australia. Lancet Reg Health West Pac (2021) 12:100193. doi: 10.1016/j.lanwpc.2021.100193

92. McMahan K, Yu J, Mercado NB, Loos C, Tostanoski LH, Chandrashekar A, et al. Correlates of Protection Against SARS-CoV-2 in Rhesus Macaques. Nature (2021) 590(7847):630-4. doi: 10.1038/s41586-020-03041-6

93. Castillo-Olivares J, Wells D, Ferrari M, Chan A, Smith P, Nadesalingam A, et al. Towards Internationally Standardised Humoral Immune Correlates of Protection From SARS-CoV-2 Infection and COVID-19 Disease. medRxiv (2021) 05(21):21257572. doi: 10.1101/2021.05.21.21257572

94. Feng S, Phillips D, White T, Sayal H, Aley PK, Bibi S, et al. Correlates of Protection Against Symptomatic and Asymptomatic SARS-CoV-2 Infection. medRxiv (2021) 2021:6. doi: 10.1101/2021.06.21.21258528

95. Wang P, Wang M, Yu J, Wang M, Yu J, Cerutti G, et al. Increased Resistance of SARS-CoV-2 Variant P.1 to Antibody Neutralization. BioRxiv (2021) 2021:3. doi: 10.1101/2021.03.01.433466

96. Tesema GA, Tessema ZT, Tamirat KS. Complete Basic Childhood Vaccination and Associated Factors Among Children Aged 12-23 Months in East Africa: A Multilevel Analysis of Recent Demographic and Health Surveys. BMC Public Health (2020) 20:1837.

Conflict of Interest: The authors declare that the research was conducted in the absence of any commercial or financial relationships that could be construed as a potential conflict of interest.

Publisher's Note: All claims expressed in this article are solely those of the authors and do not necessarily represent those of their affiliated organizations, or those of the publisher, the editors and the reviewers. Any product that may be evaluated in this article, or claim that may be made by its manufacturer, is not guaranteed or endorsed by the publisher.

Copyright $\odot 2021$ Mandala and Liu. This is an open-access article distributed under the terms of the Creative Commons Attribution License (CC BY). The use, distribution or reproduction in other forums is permitted, provided the original author(s) and the copyright owner(s) are credited and that the original publication in this journal is cited, in accordance with accepted academic practice. No use, distribution or reproduction is permitted which does not comply with these terms. 